\title{
Psychosocial Influences on Substance Abuse in a Sample of South African Youth: A Qualitative Analysis
}

\author{
Nirmala D. Gopal \\ Steven J. Collings \\ University of KwaZulu-Natal, South Africa
}

Address correspondence to Dr. Nirmala Gopal, School of Applied Human Sciences, University of KwaZulu-Natal, Durban 4041, Republic of South Africa, E-Mail: gopal@ukzn.ac.za

This study investigated the lived experience of substance abusers in the South African context. Participants were 10 individuals attending a drug treatment centre in Durban, South Africa. Data were collected using open-ended interviews with data being analysed using thematic analysis. Findings suggest that normative social influences and levels of social support play an important role in shaping, maintaining, and determining the trajectory of drug usage.

Keywords: drug use, psychosocial factors, qualitative analysis, South Africa, substance abuse

Prevalence rates for substance abuse in South Africa are extremely high, with recent estimates indicating that drug usage is twice the world norm, and with the socio-economic consequences of such usage costing the country in excess of R130 billion (US\$15.7 billion) per annum (Central Drug Authority, 2012). Findings from epidemiological studies (Plüddermann, Dada et al., 2010; Plüddermann, Flisher, McKetin, Parry, \& Lombard, 2010) indicate that alcohol, cannabis, heroin, and cocaine/crack rank amongst the most common primary substances of abuse among patients presenting at specialist treatment centres in South Africa, with the abuse of methamphetamine ('tik') being particularly high amongst adolescents in the Western Cape and 'sugars' (a low quality heroin and cocaine mix) being the primary drug of abuse among Indian males in the South Durban region.

Attempts to account for risk and protective factors for substance abuse in adolescents have focused on: bio-genetic markers (Courtney \& Polich, 2009; Kreek, Nielsen, Butelman, \& LaForge, 2005); individual factors including personality and psychopathology (White, Fleming, Catalano, \& Morris, 2006; Windle, Mun, \& Windle, 2005); as well as socio-contextual factors such as peer pressure, social norms, and neighbourhood instability (Buu et al., 2009; Perkins, Hains, \& Rice, 2005). In a recent review of the literature on risk and protective factors, Stone and her associates (Stone, Becker, Huber, \& Catalano, 2012) found support for each of these categories of risk/protective factors, but concluded that further research is required if we hope to obtain a comprehensive understanding of the mechanisms leading to problematic substance abuse.

At the present time there have been only two studies which have attempted to systematically explore risk factors for substance abuse in South Africa. In Routledge's (2005) study of 1,918 secondary school students in the Tshwane (Pretoria) area, drug use was found to be positively associated with scores on measures of both psychological well-being and life satisfaction. Similarly, in a study of risk factors for substance abuse conducted among 1,468 adolescents in Durban and Cape Town (Brook, Morojele, Pahl, \& Brook, 2006), frequency of illegal drug use was found to be most strongly associated with personal attributes (depressed mood, rebelliousness, etc.) and with peer influence.

\section{Substance Abusers Lived Experiences}

Although available epidemiological studies provide interesting insights into the dynamics of drug use, they provide us with little insight into the lived reality of substance users. Questions such as "How do substance users experience and attempt to make sense of their behaviour?" or "What do substance users believe are the influences which determine, maintain, and shape their behaviour?" cannot adequately be addressed in the context of nomothetic research methodologies which reduce all data to group averages. Although such forms of data reduction are necessary in order to both quantify and describe widespread social phenomena, what is lost in the process is an understanding of the lived experiences, and emic perspectives, of individual drug users.

\section{The Context of the Research}

We sought to investigate the lived experiences of a sample of Indian substance abusers living in the greater Durban area, South Africa. The Indian community of Chatsworth can usefully be conceptualised as a community in cultural and social transition (Desai, 2000; Pattundeen, 2008; Wassenaar, van der Veen, \& Pillay, 1998), with the instability associated with such transition having been found to be associated with a range of social ills including crime, suicidal behaviour, and substance abuse (Beekrum, Valjee, \& Collings, 2011; Mäkinen, 2000; Pattundeen, 2008; Singh \& Singh, 2007). As Pattundeen (2008) has pointed out, such cultural transition could be understood as the product of a number of social forces - including acculturation pressures, changing economic circumstances, and the milieu of change brought about by both the new democratic order and global economics - which have increasingly: (a) placed accommodation pressures on the extended patriarchal structure which characterised many traditional families, (b) created a potential for role conflict and other forms of gender tension, and (c) produced a generation of youth who are alienated from both parental values and the values of the broader community. 
These transitional pressures, combined with other social dynamics - including high rates of unemployment, divorce, and parental substance abuse - have created fertile grounds for the development of a youth culture characterised by a strong sense of alienation, a disrespect for authority, and a propensity for substance abuse (Pattundeen, 2008).

\section{Goals of the Study}

This study explored the meanings behind the narratives of young South African drug users in an attempt to chart their journey from initial contact through to the present. The following questions were addressed: (a) what were the factors which shaped and determined initial drug usage, (b) what are the factors which influenced the trajectory of drug usage, and (c) what are participant's views regarding prevention and intervention.

\section{Method}

\section{Research Design}

The study used an exploratory qualitative approach to probe insider perspectives on the substance abuse journeys of the participants. Although no specific hypotheses were entertained, it was expected that participants' narratives would provide a broader systemic perspective on the dynamics of drug use than that provided with quantitative approaches.

\section{Participants}

Participants were 10 consenting individuals (male $=90 \%$, age range $=19$ to 26 years, single $=70 \%$, ethnicity $100 \% \mathrm{ln}-$ dian) attending a drug treatment programme in the South Durban area, South Africa. The area in which the study was conducted has one of the highest rates of substance abuse in the greater Durban area (Plüdderman et al., 2010a).

\section{Data Collection}

Participants answered open-ended questions about their experiences with substance abuse relating to their initial and continued experiences of drug use. Initial questions focused on broad issues (e.g., 'Tell me about your experiences with drugs'); with secondary questions being designed to explore issues raised by participants ('Tell me why you started taking drugs'), and tertiary questions being designed to explore broader psychosocial issues (e.g., 'How did your family react to your drug use'). This sequencing of questions allowed participants to initially tell their stories in their own words, with follow-up questions being designed to elicit more detailed description and to probe issues not raised by participants.

Following Shenton (2004), attempts to ensure the credibility, transferability, and dependability of study findings included: (a) a reliance on well established and systematic methods of data reduction, (b) careful attempts to ensure that participant's consent was truly voluntary, (c) the use of iterative questioning, (c) peer scrutiny of the research project, (d) in-depth methodological description, and (e) detailed description of the phenomenon in question.

\section{Ethical Clearance}

Ethical clearance for the research was obtained from the Humanities Ethics Committee at the University of KwaZulu-Natal, with gatekeeper permission being obtained from the treatment unit. Individuals attending the treatment programme were initially briefed regarding the purpose of the research and then given a week to decide if they wished to participate in the re- search. At the end of this period 10 individuals volunteered to participate.

\section{Data Analysis}

Following transcription, the data were thematically analysed using procedures suggested by Terre Blanche, Durrheim, and Kelly (2006): familiarisation and immersion in the data, induction of themes, coding, elaboration, and interpretation/checking of themes and codes.

\section{Results}

\section{Initial Vicarious Exposure}

One of the most striking features of participants' narratives was the extent to which they reported vicarious exposure to substance abuse prior to their own decision to engage in substance abuse. For some participants this vicarious exposure involved witnessing parental substance abuse in the home, while for others the exposure involved witnessing drug usage by neighbours or school mates ('Two boys I knew were taking drugs... I used to watch them..[Eventually] I started taking sugars with them for fun' Participant 2). Many participants also reported that they had two groups of friends: those who never 'did drugs' and the 'cool' or 'main group' of friends who used drugs on a regular basis ('I had a lot of friends...most were good and never did drugs. [However] the main group influenced me to take drugs' (Participant 4).

Thus, for many participants, drug usage was effectively normalised in important social settings as well as being defined as desirable, 'cool', and/or socially acceptable. Such a dual transformation of perceptions of substance use (i.e., with respect to both normalisation and social-desirability) has been found to be strongly influential on individual's decisions to engage in substance use (King \& Chassin, 2007; Merline, Jager, \& Schulenberg, 2008; Sher \& Rutledge, 2007; Stone et al., 2012; White et al., 2008).

\section{Initial Usage}

Participants provided a variety of explanations for their initial drug usage. For a minority of participants, the progression to illegal drug usage was consistent with the 'gateway hypothesis' (Pillay, 2000) in terms of which initial use of 'legal' substances (e.g., cigarettes or alcohol) is hypothesised to lead to experimentation with 'minor' drugs (e.g., marijuana), and subsequently to the use of more dangerous substances (e.g., sugars).

However, for most participants initial drug usage was the result of normative social influence (i.e., a desire to accepted, liked, or thought of positively by others). This social influence took a number of forms, including direct peer pressure ('My friends encouraged me to take drugs' Participant 2), indirect peer pressure ('Being with people who took drugs made me want to do so' Participant 1), or more active attempts on the part of the individual to increase their social influence ('My husband was having an affair with another woman...I needed to compete for his attention by taking drugs as well' Participant 8).

These findings regarding social influence are consistent with, and extend, available findings regarding normative influences on drug usage (Stone et al., 2012); in that particular drugs (notably 'sugars') were perceived as being more strongly associated with normative social influence than others. A majority of participants (90\%) perceived the use of recently developed designed substances (such as sugars) as carrying greater psychosocial cachet than the use of more conventionally 
abused substances such as cigarettes, alcohol, or marijuana ('I had older friends who were using it [sugars]. ... and I wanted to be like them. So I started taking sugars when I was 13 years old' Participant 4).

Thus, many participants bypassed the gateway progression from 'minor' to more 'dangerous' substance usage, preferring rather to opt for sugars as a preferred drug of initial use.

\section{Social Reactions to Drug Usage}

Apart from a general sense of acceptance by the 'in-group', participants reported a range of social reactions to their drug usage. At the level of family members and non-using peers, participants experienced general disapproval of their drug taking behaviour. However, in most cases this disapproval was not associated with rejection or lack of emotional/instrumental support from either family members ('My family continued to provide moral support... and to assist in the treatment'Participant 5) or from non-using peers ('My good friends ... were pretty upset but encouraged me to stop taking drugs' Participant 10).

Social pressure to abstain from family members has been found to constitute a protective factor for escalating drug abuse trajectories (King \& Chassin, 2004; Trim, Leuthe, \& Chassin, 2006). Similarly, although peer influence has conventionally been defined as a risk factor for substance abuse (Stone et al., 2012), constructive engagement with non-abusing peers may have positively influenced treatment-seeking behaviour among participants in the present study.

Participants reporting feelings of isolation from the community at large ('I felt ostracised...people kept their distance from me'Participant 5) and a general sense of alienation ('They were talking about me behind my back...and I felt like a rogue' Participant 7). Although social isolation and a general sense of alienation may reasonably be assumed to constitute risk factors for escalating drug abuse trajectories, the impact of these variables has not been systematically explored in available studies (Stone et al., 2012); with further research on this issue being strongly indicated.

\section{Participants' Views on Prevention}

Participants noted the need for stronger resolve ('...having a positive mindset and strong will power' Participant 10), finding a purpose in life ('Having goals...one should strive for and work at' Participant 7) and the need for engagement in constructive activities ('Becoming involved in recreational activities so as not to become idle' Participant 9). At an interpersonal level, recommendations included the avoidance of contact with drug users ('Stop being with friends who take drugs and join those who aren't taking drugs' Participant 3) and the need for an increased reliance on family advice and support ('Listen to your parents and maybe...you will get a nice job and achieve a lot' Participant 1).

At a broader level, many participants believed that there was a need to challenge the notion of drug usage as an easy shortcut to social acceptance. According to participants there was a need for youth to be exposed to educational materials on the risks of drug usage ('Creating awareness about the reality of drugs' Participant 6) and, most importantly, a need for youth to be exposed to the harsh realities of drug usage ('They need to come and see me when I'm withdrawing and see what's happening to me' Participant 8).

\section{Discussion}

The findings of the present study suggest that some South African Indian youth are raised in a context which provides numerous opportunities for vicarious exposure to substance abuse. The ubiquitous nature of such exposure (at home, at school, and in the neighbourhood) creates a context in which the idea of drug usage is hard to ignore and in which: (a) the use of drugs is normalised and defined as socially acceptable, (b) drug usage is seen to constitute a readily accessible, and effective, strategy for achieving normative social influence, and (c) the use of more dangerous or addictive substances is viewed as carrying greater psychosocial cachet. As such it is hardly surprising that many youth are drawn into a web of drug usage, with more dangerous/addictive drugs (e.g., 'sugars') often being the initial drug of choice.

Findings regarding social reactions to drug usage indicate that while many users continue to receive constructive support from family members and non-using peers, the community in general is decidedly less supportive, with this lack of support engendering feelings of isolation and alienation. This latter finding replicates and extends findings from previous studies which have identified alienation and isolation as risk factors for substance abuse (Pattundeen, 2008), with the extension to previous findings lying in the present findings that alienation and isolation may constitute both a risk factor for, and a consequence of, drug usage. As such there is a potential for drug users to find themselves enmeshed in a repeated cycle of drug usage, involving: (a) initial drug usage (as a strategy for achieving social recognition), (b) community isolation and alienation as a consequence of drug usage, followed by (c) further drug usage in an attempt to regain lost social recognition.

\section{Conclusion}

The present study identified various psychosocial factors which would appear to play an important role in both substance use and in treatment seeking behaviour. Study findings suggest that constructive support provided by family members and non-abusing peers may assist recovery efforts.

\section{References}

Beekrum, R., Valjee, S. R., \& Collings, S. J. (2011). An emic perspective on the dynamics of non-fatal suicidal behaviour in a sample of South African Indian women. South African Journal of Psychology, 41, 63-73.

Brook, J. S., Morojele, N. K., Pahl, K., \& Brook, D. W. (2006). Predictors of drug use among South African adolescents. Journal of Adolescent Health, 38, 26-34.

Buu, A., Dipiazza, C., Wang, J., Puttler, L. I., Fitzgerald, H. E., \& Zucker, R. A. (2009). Parent, family, and neighbourhood effects on the development of child substance abuse and other psychopathology from preschool to the start of adulthood. Journal of Studies on Alcohol and Drugs, 70, 489-498.

Central Drug Authority. (2012, April). Substance use and abuse in South Africa. Paper presented at the National Mental Health Summit, Pretoria, South Africa.

Courtney, K. E., \& Polich, J. (2009). Binge drinking in young adults: Data, definitions, and determinants. Psychological Bulletin, 135, 142-156.

Desai, A. (2002). We are the poors. New York, NY: Monthly Review Press. 
King, K. M., \& Chassin, L. (2004). Mediating and moderating effects of adolescent behavioral undercontrol and parenting in the prediction of drug use disorders in emerging adulthood. Psychology of Addictive Behaviors, 18, 239-249.

King, K. M., \& Chassin, L. (2007). A prospective study of the effects of age of initiation of alcohol and drug use on young adult substance dependence. Journal of Studies on Alcohol and Drugs, 68, 256-265.

Kreek, M. J., Nielsen, D. A., Butelman, E. R., \& LaForge, K. S. (2005). Genetic influences on impulsivity, risk taking, stress responsivity and vulnerability to drug abuse and addiction. Nature Neuroscience, 8, 1450-1457.

Mäkinen, I. H. (2000). Eastern European transition and suicide mortality. Social Science and Medicine, 51, 1405-1420.

Merline A., Jager, J., \& Schulenberg, J. E. (2008). Adolescent risk factors for adult alcohol use and abuse: Stability and change of predictive value across early and middle adulthood. Addiction, 103, 84-99.

Pattundeen, G. (2008). Missing out on migration: "Sugars" and the post-apartheid youth of Chatsworth. Journal of Social Sciences Special Volume, 10, 61-71.

Perkins, H. W., Haines, M. P., \& Rice, R. (2005). Misperceiving the college drinking norm and related problems: A nationwide study of exposure to prevention information, perceived norms and student alcohol misuse. Journal of Studies on Alcohol and Drugs, 66, 470-478.

Pillay, K. (2000). Schools-based crime prevention with specific reference to the prevention of drug abuse. Acta Criminologica, 13, 72-79.

Plüdderman, A., Dada, S., Parry, C., Bhana, A., Bachoo, S., Perreira, ... Freytag, K. (2010). Monitoring alcohol and drug abuse trends in South Africa (July 1996-June 2010). South African Community Epidemiology Network on Drug Abuse, Research Brief, 13, 1-15.

Plüdderman, A., Flisher, A. J., McKetin, R., Parry, C., \& Lombard, C. (2010). Methamphetamine use, aggressive behaviour, and other mental health issues among high school students in Cape Town, South Africa. Drug and Alcohol Dependence, 109, 14-19.

Routledge, L. (2007). Substance abuse and psychological well-being of South African adolescents in an urban context (Unpublished master's dissertation). University of Pretoria, South Africa.

Shenton, A. K. (2004). Strategies for ensuring trustworthiness in qualitative research projects. Education for Information, 22, 63-75.

Sher, K. J., \& Rutledge, P. C. (2007). Heavy drinking across the transition to college: Predicting first semester heavy drinking from precollege variables. Addictive Behaviors, 32 819-835.

Singh, A., \& Singh, S. (2006). The history of crime among people of Indian origin in South Africa. Anthropologist, 8, 147-156.

Stone, A. L., Becker, L. G., Huber, A. M., \& Catalano, R. F. (2012). Review of risk and protective factors of substance use and problem use in emerging adults. Addictive Behaviors, 37, 747-775.

Terre Blanche, M., Durrheim, K., \& Kelly, K. (2006). Research in practice: Applied methods for the social sciences. Cape Town, South Africa: University of Cape Town Press.
Trim, R. S., Leuthe, E., \& Chassin, L. (2006). Sibling influence on alcohol use in a young adult, high risk sample. Journal of Studies on Alcohol and Drugs, 67, 391-398.

Wassenaar, D. R., van der Veen, M. B. W., \& Pillay, A. L. (1998). Women in cultural transition: Suicidal behaviour in South African Indian women. Suicide \& Life-Threatening Behavior, 28, 82-93.

White, H. R., Fleming., C. B., Catalano, R. F., \& McMorris, B. J. (2008). Identifying two potential mechanisms for changes in alcohol use among college-attending and non-college-attending emerging adults. Developmental Psychology, 44, 1625-1639.

White, H. R., McMorris, B. J., Catalano, R. F., Fleming, C. B., Haggerty, K. P., \& Abbott, R. D. (2006). Increases in alcohol and marijuana use during the transition out of high school into emerging adulthood: The effects of leaving home, going to college, and high school protective factors. Journal of Studies on Alcohol and Drugs, 67, 810-822.

Windle, M., Mun, E. Y., \& Windle, R. C. (2005). Adolescent-to-young adulthood heavy drinking trajectories and their prospective predictors. Journal of Studies on Alcohol and Drugs, 66, 313-322.

\section{Author Notes}

The authors wish to acknowledge the contribution of Predeshni Murugas who assisted with data collection. 
Copyright of Journal of Psychology in Africa is the property of Elliott \& Fitzpatrick, Inc. and its content may not be copied or emailed to multiple sites or posted to a listserv without the copyright holder's express written permission. However, users may print, download, or email articles for individual use. 